تحديد قدرة التحليل الطاقي لكاشف الأثر النووي LR-115 باستخدام مجموعة برامج Matlab

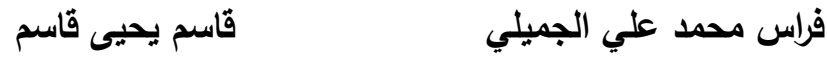

$$
\begin{aligned}
& \text { قسم الفيزياء/ كلية العلوم/ جامعة الموصل } \\
& \text { (أستلم 15/ } 1 \text { /2014 ؛ قُبل } 24 \text { /2014) } \\
& \text { الملخص }
\end{aligned}
$$

يهدف البحث إلى تحديد قدرة التحليل الطاقي للكاثف LR-115 على التمييز بين الطاقات المختلفة لجسيمات ألفا المستحصلة من مصدر الأميريشيوم Am ${ }^{241}$ فضلاً عن تحسين كفاءته من خلال التحري واستقصاء عدد الآثار المتخلفة على مادة الكاشف والتي لهاتي تم إظهارها بعد المعالجة الكيميائية للكاشف عند ظروف قشطيه (NaOH, 2.5N, 60 C). استخدمت برامج حاسوبيه بأسم ( Gauss)

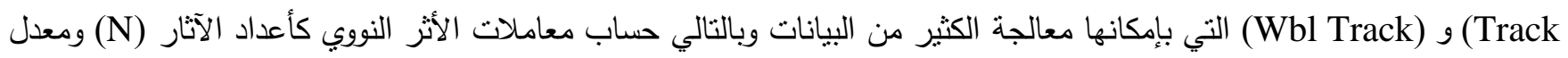
أقطارها (D) ومعدل مساحاتها (A). حُددت قدرة التحليل الطاقي للكاشف (R) من خلال معادلة قدرة التحليل الطاقي بدلالة قطر الأثر ( $2 \mathrm{E} / \mathrm{E})_{\mathrm{D}}$ عند زمن القتشط الأمنل الذي يحصل عنده أقل انحراف معياري لإُطياف التوزيع. أُعِدَ برنامج من قبلنا سمي (Edge Track) وباستعمال المشغلات (Roberts, Prewitt, Canny, Sobel, Zero-cross, Log) للكثف عن حافات الآثار (محيطها) لدراسة تأثير تلك التقنية على خواص الكاشف من حيث قدرته التحليلية وكفاءته في الكثف عن اثار جديدة، وتبين أن المشغل (Roberts) يمتلك إمكانية عالية على استقصاء الآثار والذي أنعكس ايجاباً على كفاءة الكاثف. أظهرت تلأك التقنية تأثيراً ايجابياً على قدرة التحليل

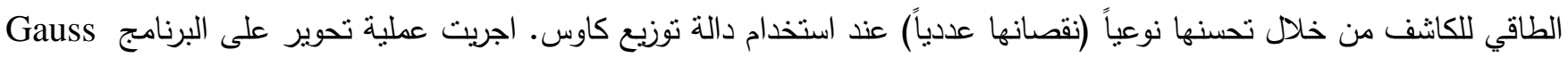
Track ليتم بعدها الحصول على برنامج مشابه له سمي Area Gauss Track بعد إجراء الملاعمة مابين مكررات كثافة الآثار طبقاً لمساحاتها وقد تم ذلك قبل إدخال تقنية كثف الحافة وبعدها التي أظهرت تحسُناً نوعياً على خاصية الكاثف التحليلية. وجد أن قدرة التحليل الطاقي أفضل عند الطاقات العليا مما هي للطاقات الواطئة ضمن المدى المستخدم.

الكلمات الدالة: توزيع كاوس ، توزيع وييل، تقنية كثف الحافة ، قدرة التحليل الطاقي، كاثف الأثر النووي LR-115 .

\title{
Determination of the Energy Resolution for Nuclear Track Detector LR-115 Using Matab Software
}

\section{Firas M. AL-Jomaily Kasim Y. Kasim \\ Department of physics/College of Science/University of Mosul}

ABSTRACT

The aim of this research to determine the energy resolution of the nuclear detector LR-115 to distinguish between the different energies of alpha particles which were obtained from the source amiricium $\left({ }^{241} \mathrm{Am}\right)$ as well as improve its efficiency through investigation and detect the number of deposited tracks on the material detector which was shown after the chemical treatment of the detector when the etching conditions $\left(\mathrm{NaOH}, 2.5 \mathrm{~N}, 60^{\circ} \mathrm{C}\right)$.We have been using computer programs named (Gauss Track) and (Wbl Track), which can handle a lot of data and thus measure parameters of nuclear track as numbers of tracks (N) and average diameters (D) and its average area (A). Where the Energy 


$$
\text { فراس محمد علي الجميلي و قاسم يحيى قاسم }
$$

resolution of detector $(\mathrm{R})$ was determined by the equation of energy resolution in terms of the diameter's track $(\Delta \mathrm{E} / \mathrm{E})_{\mathrm{D}}$ and by the two programs mentioned above and which contain Gauss distribution function and distribution function of Weibull respectively. This has been done at the optimum time of etching, where the least standard deviation of the spectrum distribution happened.We also prepared a program named (Edge Track) and by using the operators (Roberts, Prewitt, Canny, Sobel, Zero-cross, Log) to detect the edges of tracks and theor circumference to study the effect of that technique on the properties of the detector via its analysis ability and efficiency to detect another tracks. It has been shown that the operator (Roberts) has a high potential to detect the tracks which reflected positively on the efficiency of the detector. It also showed this technique has a positive effect on the ability of the energy resolution of the detector through improvement qualitatively (decreasing numerically) when we use Gaussian function. Also a modified operation has been done on the Gauss Track program to obtain a program similar to it, we called (Area Gauss Track) after making a fitting between replicates of the intensity of the tracks according to its area which has been done before and after the using the Edge detection technique which showed a qualitative improvement on the property analytical detector. It has been found that the ability of energy resolution at higher energies better than with lower ones within the range of user.

Keywords:Gaussian distribution, weibull distribution, edge detectiont, energy resolution, nuclear track detector LR-115.

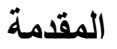

تتصف كواشف الأثر النووي ولاسيما الكاشف LR-115 بقابليتها على تمييز الطاقات (تحليل الطاقات) فضلاً عن كفاءتها وقابليتها على كثف وتسجيل الجسيمات المشحونة كآثار نووية مستترة. ويختلف ذلك من كاشف إلى أخر بسبب اختلاف صفات المواد الداخلة في تركيب الكاشف إن قدرة التحليل هي قابلية الكاثف على التمييز بين قمنين متجاورتين ومنقاربتين في الطاقة (عبداله وآخرون، 1990). وقد بذلت جهود كبيرة لتحسين أداء تلك الكواثف على إظهار الآثار النووية بإلاعتماد على طرائق تقليدية للوصول

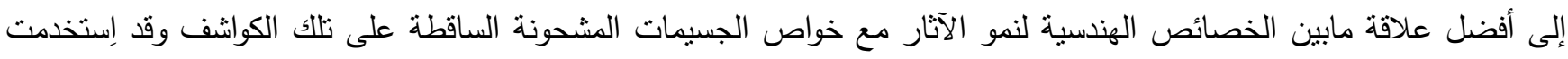
تلك التطورات حتى نت الوصول إلى تقنيات المعالجة الصورية للآثار النووية. كُتبَّ برنامج من قبل(Patiris et al., 2006) سمي TRIAC-A بلغة ماتلاب ليتمكنوا من تحسين صوّر الآثار النووية وحساب عدد من العوامل الأخرى المتعلقة بشكل الأثر من خلال التحليل الصوري إذ تصنف الآثار طبقاً لأقطارها لدراسة إمكانية استخدام

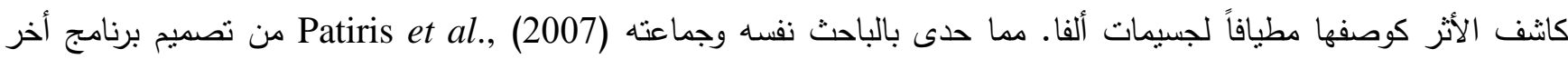

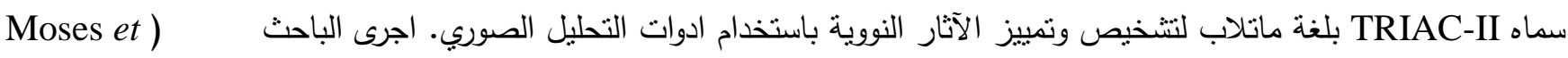

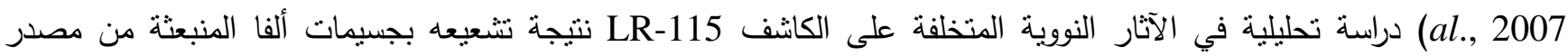
الأميريشيوم Am عن معاملات الأثر الأخرى كقطر الأثز النووي والمحور الكبير والصغير وبعض العمليات الإحصائية الأخرى بمعدل زمني لا لأني يتجاوز sec 3.5. تحرى كل من (Zaki and EL-Shaer, 2007) عن قدرة التحليل الطاقي لنوعين مختلفين من الكاشف CR-39 حيث تم تشعيع الكواثف بجسيمات ألفا المنبعثة من مصدر 3.57 Am

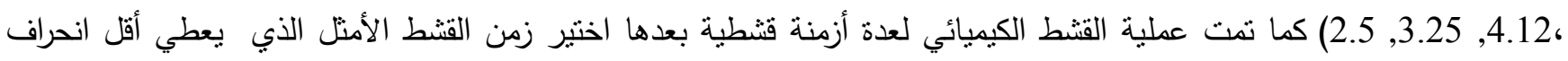


معياري لأطياف جسيمات ألفا وكان بحدود (35h) وحدد عرض الذروة عند كل طيف طاقي مستخدم فضلاً عن معدل أقطار الآثار

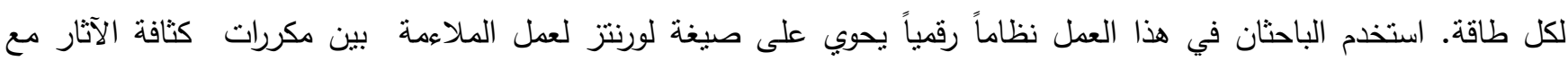
أقطارها ووجدوا بأن قدرة التحليل تتحسن نوعياً (تقل عدديا) مع زيادة طاقات جسيمات ألفا الساقطة. بيّن (الجبوري، 2004) أن قدرة التحليل الطاقي للكاثف PM-355 عند الطاقات العالية أفضل مما للطاقات الواطئة. إن من إحدى العوامل المؤثرة في قدرة التحليل الطافي وضوح حوافات الأثر على سطح الكاشف وقامت الباحثة (العريبي، 2008) باستخدام خوارزميات تحسين الصور لما لها من

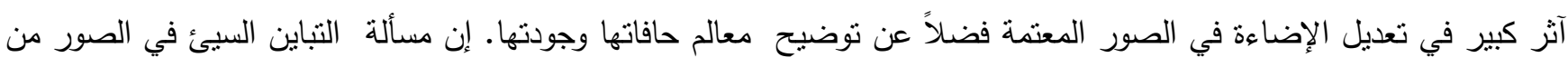
أكثر المشاكل التي تواجه المستخدمين أو الباحثن لدى عمهم في صور علمية أو في حالة الاستخدام العام للصور وهذه الخوارزمية

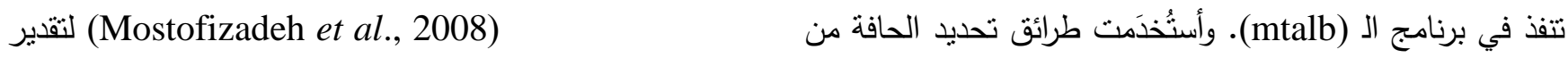
دقة وإتقان الأثز النووي الكثيف في كواثف الأثر النووي ومن الممكن أن تتفذ القياسات بحالتين قبل تحسين صورة الأثر وبعدها. كما تراعي ظاهرة تداخل الأثر المتضمنة تداخلين أو ثلاثة تداخلات. كما أجرى الباحثون (Amero et al., 2001) عملية تحليليه

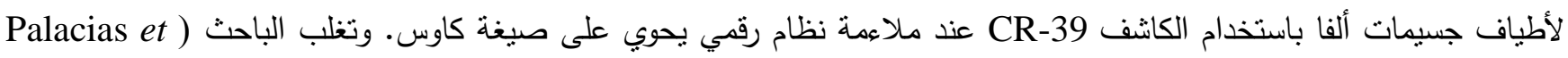
al.2011) وجماعته على تداخل الآثار النووية المتخلفة في مادة الكاثف فضلاً عن تباين أقطارها بالرغم من سقوط جسيمات ألفا على سطح مادة الكاشف عامودياً وبطاقة أحادية و نم ذلك بنطبيق خاصية التوزيع الكاوسي عند دراسة العلاقة بين مكررات كثافة الآثار مع أقطارها.

تهدف در استتا الحالية معالجة صورية لأسطح كاثنف الأثر قدرة التحليل الطاقي وأمكانية تحسين كفاءته في التحري على آثار نووية أخرى من خلال مؤشر إحصاء وعّد الآثار بعد إدخال تقنية

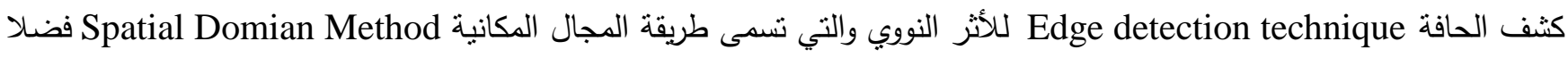
عن إمكانية تحسين قدرة التحليل الطاقي لكونها غنية بالمعلومات والمعطيات المفيدة التي توفرها تلك الطريقة ولاسيما حصولنا على حدود حافات الأثر النووي. الجزء النظري

تباين الطاقة والتوزيع الكاوسي : تتضمن القياسات المعتمدة على ملاحظة التحلل الإثعاعي تراوحاً إحصائياً بسبب اللادقة في القياسات النووية و بسبب حصول تباين في مقدار الطاقة المفقودة على طول مسار الجسيم الساقط فضلا عن ان ظاهرة النشاط الإشعاعي عملية إحصائية وعشوائية ولايمكن إزالة هذه اللادقة بل يمكن التقليل من أثنارها بأساليب مختلفة ويمكن تقريب التوزيع الطاقي إلى دالة كاوس

$$
f(x)=\frac{1}{\sigma \sqrt{2 \pi}} e^{-\frac{(x-\mu)^{2}}{2 \sigma^{2}}}
$$$$
\text { وآخرون،1990). والذي يعبر عنه بالمعادلة الآتية }
$$ 


$$
\text { فراس محمد علي الجميلي و قاسم يحيى قاسم }
$$

\section{توزيع وييل :}

دالة التوزيع لوييل هي دالة الاحتمالية المستمرة سميت بعد أن Waloddi Weibull وصفها بالتقصيل عام 1951 بالرغم أنس أن أول

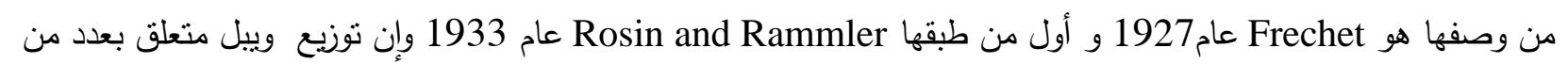

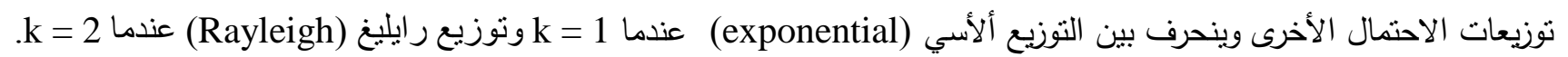
ويعبر عن صيغة وييل كما في المعادلة في أدناه.

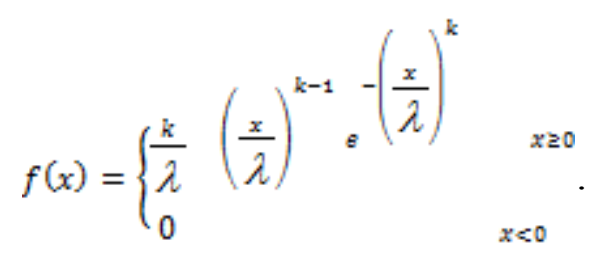

حيث $\lambda$ عامل القياس ، و k عامل الثنكل. واعتمد توزيع وييل بوصفه أحد الأجزاء الاساسيه الأخرى في دراستتا الحالية فضلاً عن توزيع كاوس كما ذكرنا ذلك في الفقرة السابقة

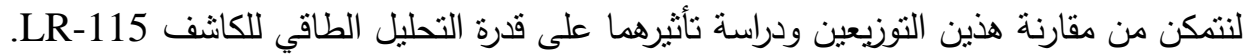

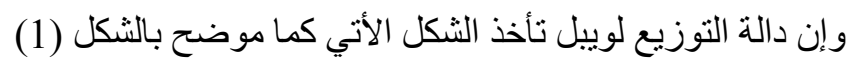

density

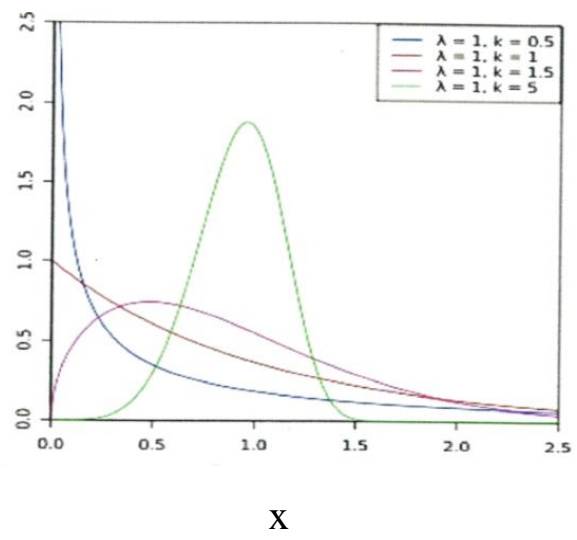

\section{الثكل1: دالة توزيع وييل (Muraleedharan et al.,2007).}

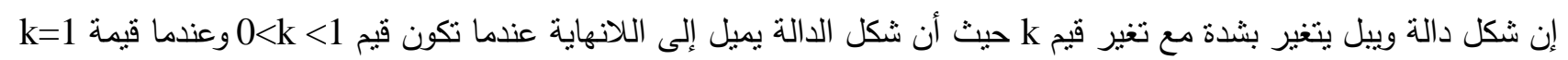

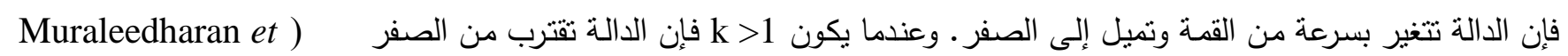
.(al., 2007

تقنية حافة الأثر (Edge Detection Technique):

تعرف الحافة بشكل عام أنها الحدود التي تفصل مناطق متجاورة من الصور لها تباين متميز في السطوع. أوهي خيط رفيع يمرر

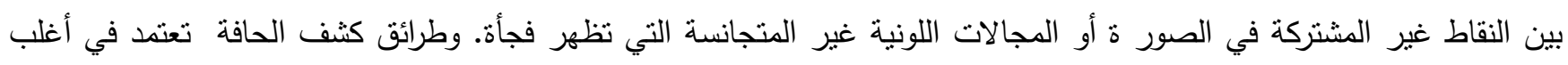
الأحيان على ميزات خاصة في الصورة. إن الكثف عن الحافة يلعب دورا حيويا في رؤية الحاسوب ومعالجة الصور ـ وحافة الصورة 
واحدة من الميزات الأكثر أهمية التي تستخدم أساسا لعملية تحليل الصورة فضلاً عن عملية تمييز الأنماط (pattern recognition)

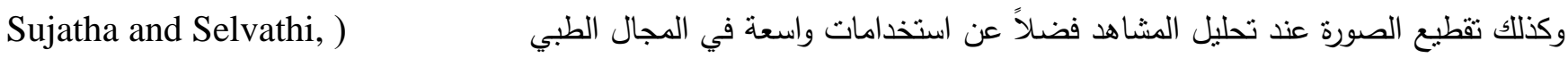
2012). إن كثف الحافة من أهم التقنيات التي من خلالها تتم معرفة مكونات الصورة المهمة. وتعتمد طرائق كثف الحافة بشكل عام على استخدام مصفوفة الانحدار (الميل) التي من خلالها تكثف نقاط الصور(pixels) ذات التغير السريع في شدتها وهذه التقنية تتفذ عادة باستخدام عمليات المشتقة من الرتبة الأولى والثانية لكل نقطة من الصورة وتنتخدم المشتقة من المرتبة الأولى لتحديد نقاط

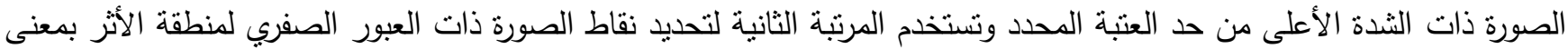
التقاء المنحني مع المحور (Zero-cross points) x كما مبين في الثكل (2).

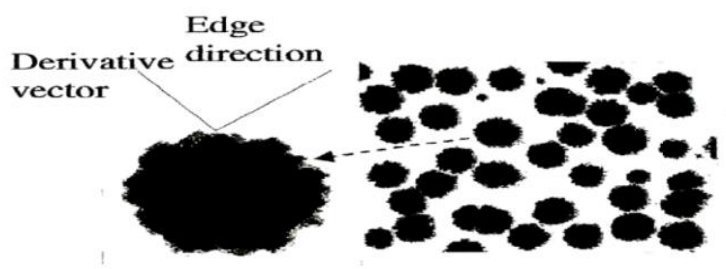

الثكل 2: يوضح اتجاه متجه الحافة على نقطة افتراضية من مسار الأثر(Mostofizadeh et al., 2008) ومن مشغلات كثف الحافة الششهورة سوبل (Sobel) وبرويت (Prewitt) و روبرت (Roberts) الني تشتخدم المصفوفات الخاصة بالمشتقة هذه التقنيات تعيد نقاط الصور ذات التدرجات اللونية إلى الصور الأصلية. أما تقنيات لابلاس من كاوس(Log) و و العبور الصفري (Zero-crossing) تقوم بمعايرة صفرية للصورة بعد تصفية الصورة الأصلية. وفي عام 1986 قدم كاني (Canny)

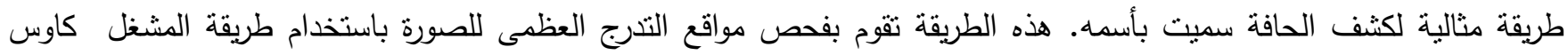
لحساب التدرج اللوني للصور (Mostofizadeh et al., 2008).

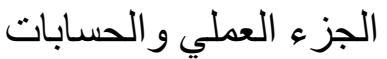

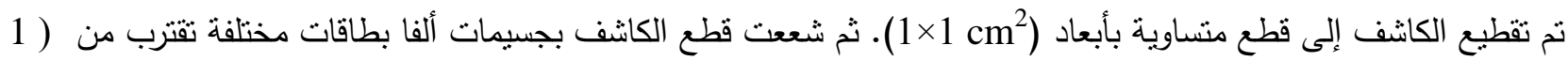
4.2 MeV $\mathrm{E}_{\alpha}=\mathrm{E}_{0}\left[1-\frac{\mathrm{x}}{\mathrm{R}_{\mathrm{a}}}\right]^{\frac{\pi}{2}}$ لجسيمات ألفا في الهواء وباستخدام المعادلة الآتية (Cember,1996)

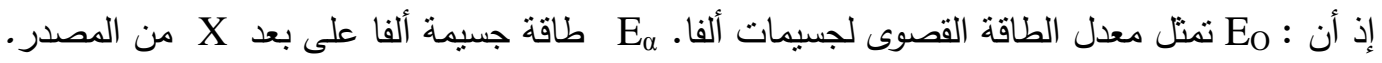

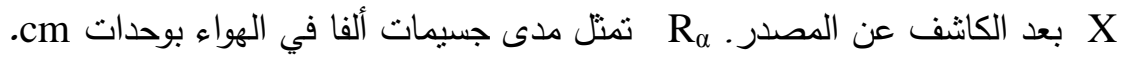
وتجدر الإشـارة إلى أن عملية التشعيع أجُريت على منطقة صغيرة من سطح الكاشف لاتتجاوز 1.5mm وبزاويـة مجسمة قليلة جداً

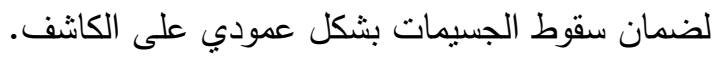

ولإظهار الآثار المتكونـة في الكاشف اعتمد القتشط الكيميائي باستخدام المحلول NaOH بتركيز $2.5 \mathrm{~N}$ ودرجة حرارة Co ولأزمنة قشطية مختلفة وبتتابع زمني كل ربع ساعة لحين حصول الاندماج الكلي للآثار في الكاشف (60min - 150min) وبعد كل Digital Eye Pieces مكلة قنطية نقوم بأخذ صورة رقمية للكاشف عن طريق كاميرة رقمية من نوع إنتاج شركة

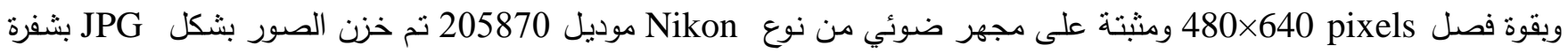




$$
\text { فراس محمد علي الجميلي و قاسم يحيى قاسم }
$$

معينة تميز الكاشف المستخدم وتحول إلى خانـة الـ Work في برنـامج ماتلاب. وبعدها ينت تشغيل البرامج المصممة والمكتوبـة في

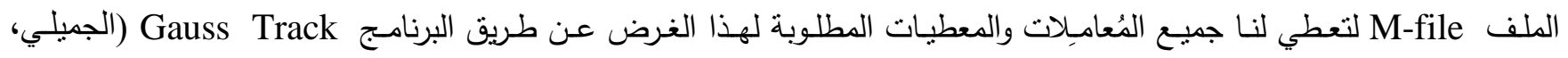
2009) وبرنامج Wb1 Track على التوالي. تم الحصول على أطياف التوزيع لتباينات أقطار الأثر ومكررات كثافتها العددية لكل طاقة لتحنة مدروسـة عند زمن القتط الأمثل (120min) الذي يظهر أقل انحراف معياري للتوزيعين المذكورين أعلاه. ليتم بعدها حسـاب قدرة

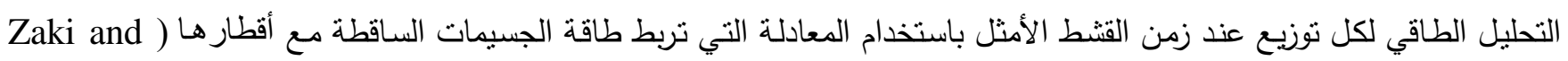
(EL-Share, 2007

$$
\frac{\mathrm{dE}}{\mathrm{E}}=\frac{\left(\mathrm{E}_{2-} \mathrm{E}_{1}\right) /\left(\mathrm{D}_{2-} \mathrm{D}_{1}\right)}{0.5\left(\mathrm{E}_{2}+\mathrm{E}_{1}\right)} \Delta \mathrm{D}
$$

إذ أن : $\mathrm{D}_{1}$ و يمثلان معدل أقطار الآثار المقابلة للطاقتنين موضح بالثكل (3).

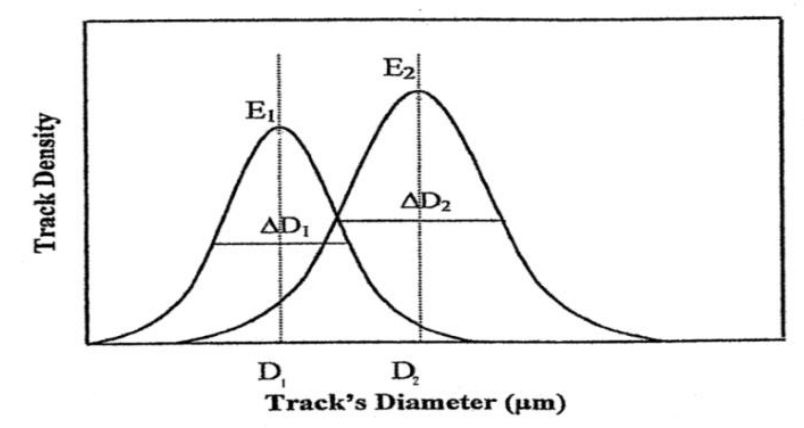

\section{الثكل 3: طيف التوزيع لمعدل أقطار الآثار ومكرراتها}

كما تم حساب عدد الآثار في كلا التوزيعين لإمكانية استخدامهما كمؤشر على كفاءة الكاثف في التحري على الآثار وعدها. تقنية كشف الحافة (Edge detection Technique):

استخدمت تقنية كثف حافة الأثر النووي ولجميع أنواع المشغلات (روبرت Roberts ،سوبل Sobel ، برويت Srewitt

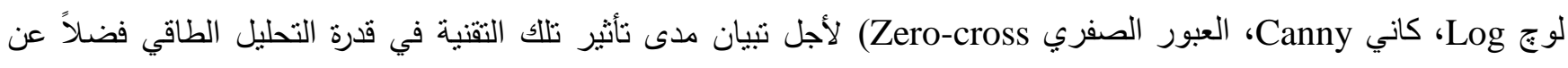
إمكانية إظهار آثار نووية إضافية لم تؤخذ بنظر الاعتبار في عملية العد قبل اخذ الحافة كما يمكن استعمال تلك التقنية للتغلب على ظاهرة التداخل (overlapping phenomen) التي تحدث في الآثار النووية. طُبقت المشغلات المذكورة في أعلاه التي تُعرف تُونة بالمشغلات القابلة للشتقاق derivative operators والتي نطبق على الصورة الأصلية لسطح الكاشف إذ ينم تحويل الصورة الأصلية إلى صورة ثنائية binary image والمتشكلة بنفس حجم الصورة الأصلية. إن النقاط العشوائية (pixels) المكتشفة كحافات للأثر النووي تعود إلى أعلى الثدة (1) وباقي النقاط الضوئية تعود إلى أقل شده (0) كما سنرى جميع أصناف الصور تكون ثنائية

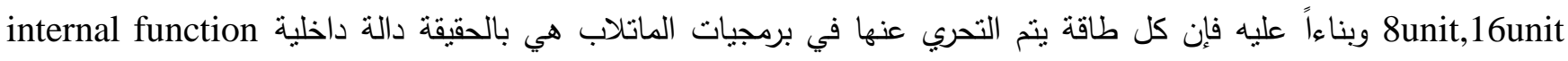
والتي بإمكانها أن تحول المسنويات الرمادية للصور image gray levels إلى (0,1) (0,255) (0,65535) ولكل من أصناف 8unit,16unit على التوالي، ولذا فإن الثدات الصفرية يمكن عدها مظلمة (Dark dots) (0)، والثدات العالية الواقعة في محيط الأثز يمكن عدها بيضاء براقة والتي تأخذ (1,250,65535). أما في عملنا الحالي فسوف نلحظ بأن حافات الآثار ملونة لكوننا قمنا 
بتحويل الصور الثتائية إلى الخارطة اللونية المزيفة لتسهيل عملية إحصاء عدد الآثار وتحليلها ومن ثم تحويلها إلى مدرجات تكرارية تصف مكررات عدد الآثار طبقاً لأقطارها. والثكل (4) يعبر عن المخطط الانسيابي للبرنامج المعد من قبلنا وسمي (Edge Track) الذي يمكن من خلاله الحصول على حافات الآثار النووية ولكل طاقة مستخدمة. بعدها نم إدخال تلك التقنية وبمشغلاتها المستخدمة على البرنامجين Wbl Track ،Gauss Track بطريقة تحوير مناسبة ذلك لحساب عدد من خواص الكاثف كقدرة التحليل الطاقي وعدد الآثار المتخلفة على مادة الكاثف بعد إدخال تلاك التقنية لتبيان تأثثر هذه التقنية

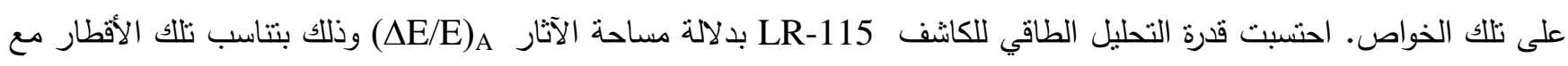
مساحاتها (pixels) وقد نم ذلك بعد الحصول على معدل مساحات الآثار (A) لكل طاقة ومعدل عرضها (AA) بطريقة مشابهه لإستخدام أقطار الآثار وعرض أطيافها و نم ذلك بعد إجراء عملية تحوير على البرنامج Gauss Track لنحصل في الأخير على

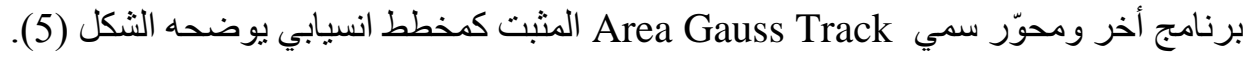

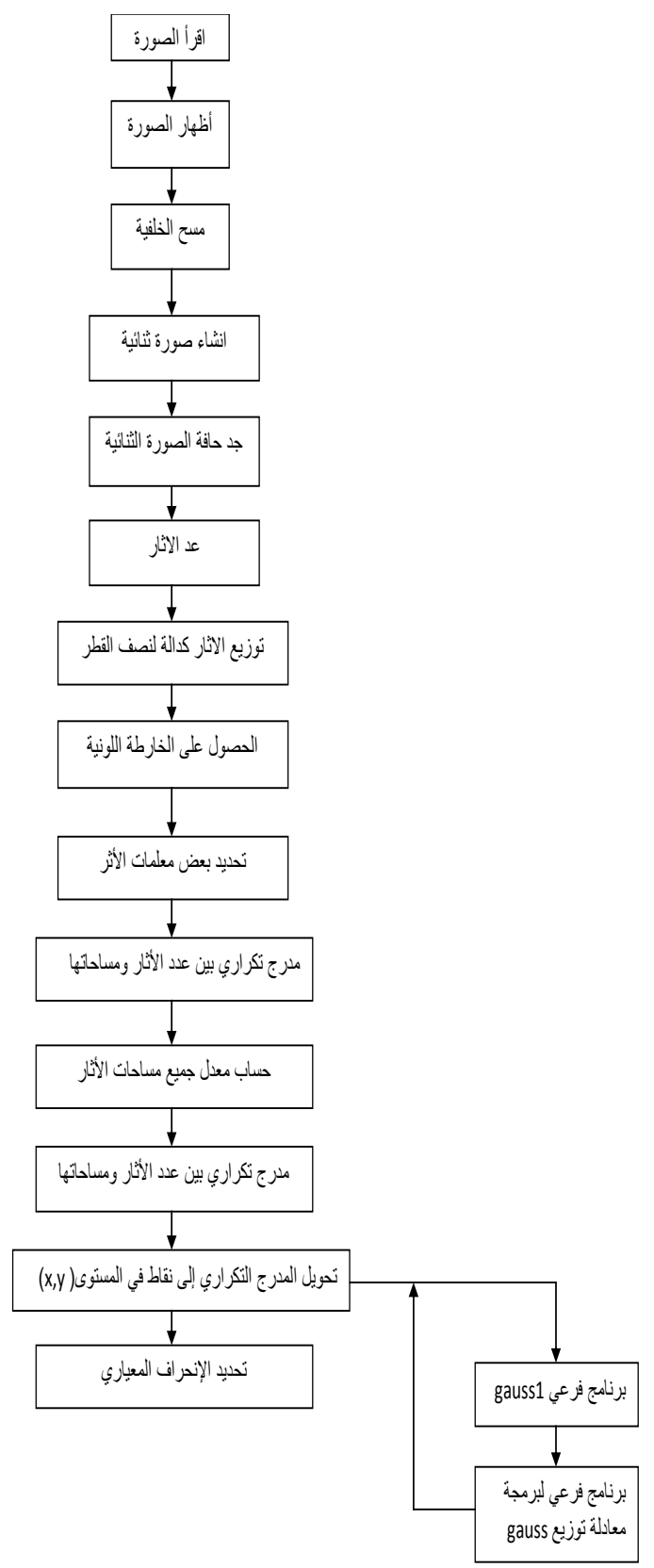

Area Gauss Track الشكل 5: المخطط الانسيابي لبرنامج 


$$
\text { فراس محمد علي الجميلي و قاسم يحيى قاسم }
$$

يتم بعدها دراسة تأثير تلك الملاعمة على قدرة التحليل الطاقي للكاشف. حيث من الممكن تحوير العلاقة (L/E) بدلالة القطر إلى علاقة بدلالة المساحة. لنحصل على

$$
\left(\frac{\Delta E}{E}\right)_{A}=\frac{E_{1}-E_{2}}{0.5\left(E_{1}+E_{1}\right)} \times \frac{\Delta A}{\left(\mathrm{~A}_{1}-\mathrm{A}_{2}\right)}
$$

إذ أن : A و A A A A A معل عرض مساحة الآثار المقابلة للطاقتين E هA معدل عرض الطيف للطاقتين المتجاورتين .

\section{النتائج والمناقشة}

لأجـل دراسـة قابليـة الكانـف LR-115 على التمبيز بـين الطاقـات

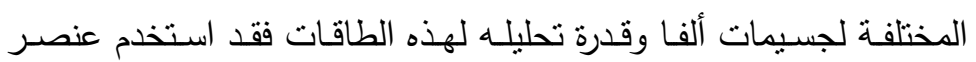
الأميريشيوم Am ${ }^{241}$ للحصول على جسيمات ألفا وبطاقات متعددة وذلك وفي

لعدم توفر مصادر قياسية لانبعاث جسيمات ألفا بطاقات مختلفة. تم إجراء المعالجات الصورية للكاشف LR-115 من خلال برنامج Gauss Track قدرة تحليـل طـاقي للكاثـف وأقـل إنحـراف معيـاري الــي بـدوره يعطينـا معاملات الأثر وخواص الكاشف LR-115 كما مبين في الجدول (1). اجريت الملاعمة بين مكررات اعداد الآثار طبقاً لأقطارها وللطاقات جميعها بعد إجراء عملية الملاءمـة باستخدام توزيـع كاوس كمـا مبين في الثكل

الجدول 1: أعداد الآثار(No.) وأقطارها (D) وعرض الطيف

الشكل 4: المخطط الانسيابي لبرنامج Edge Track

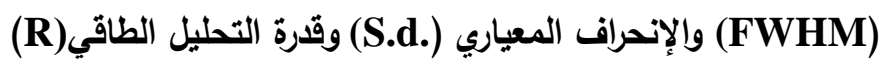

للكاشف LR-115 وللطاقات جميعها عند زمن القشط الأمثل

\begin{tabular}{|c|c|c|c|c|c|}
\hline Energy $(\mathrm{MeV})$ & $\mathrm{D}(\mu \mathrm{m})$ & $\mathrm{FWHM}(\mu \mathrm{m})$ & S.d. & $\mathrm{R}$ & No.of track \\
\hline 1 & 7.6176 & 1.6957 & 0.7203 & & 56 \\
\hline 1.4 & 10.1991 & 2.7748 & 1.1788 & 0.1443 & 59 \\
\hline 1.8 & 11.097 & 3.3313 & 1.4152 & 0.4250 & 69 \\
\hline 2.2 & 10.2423 & 1.9129 & 0.8126 & 0.3068 & 123 \\
\hline 2.6 & 9.3744 & 2.3090 & 0.9809 & 0.2027 & 84 \\
\hline 3 & 8.0962 & 3.2777 & 1.3924 & 0.1561 & 116 \\
\hline
\end{tabular}




\begin{tabular}{|l|l|l|l|l|l|}
\hline 3.4 & 6.8443 & 1.788 & 0.7595 & 0.1263 & 141 \\
\hline 3.8 & 5.3818 & 1.8235 & 0.7747 & 0.0686 & 186 \\
\hline 4.2 & 3.4189 & 2.6872 & 1.1415 & 0.0574 & 237 \\
\hline
\end{tabular}

يبين الثكل (6) العلاقة بين مكررات كثافة اعداد الآثار طبقاً لأقطارها وللطاقات المستخدمة جميعها بعد إجراء عملية الملاعمة باستخدام توزيع كاوس.
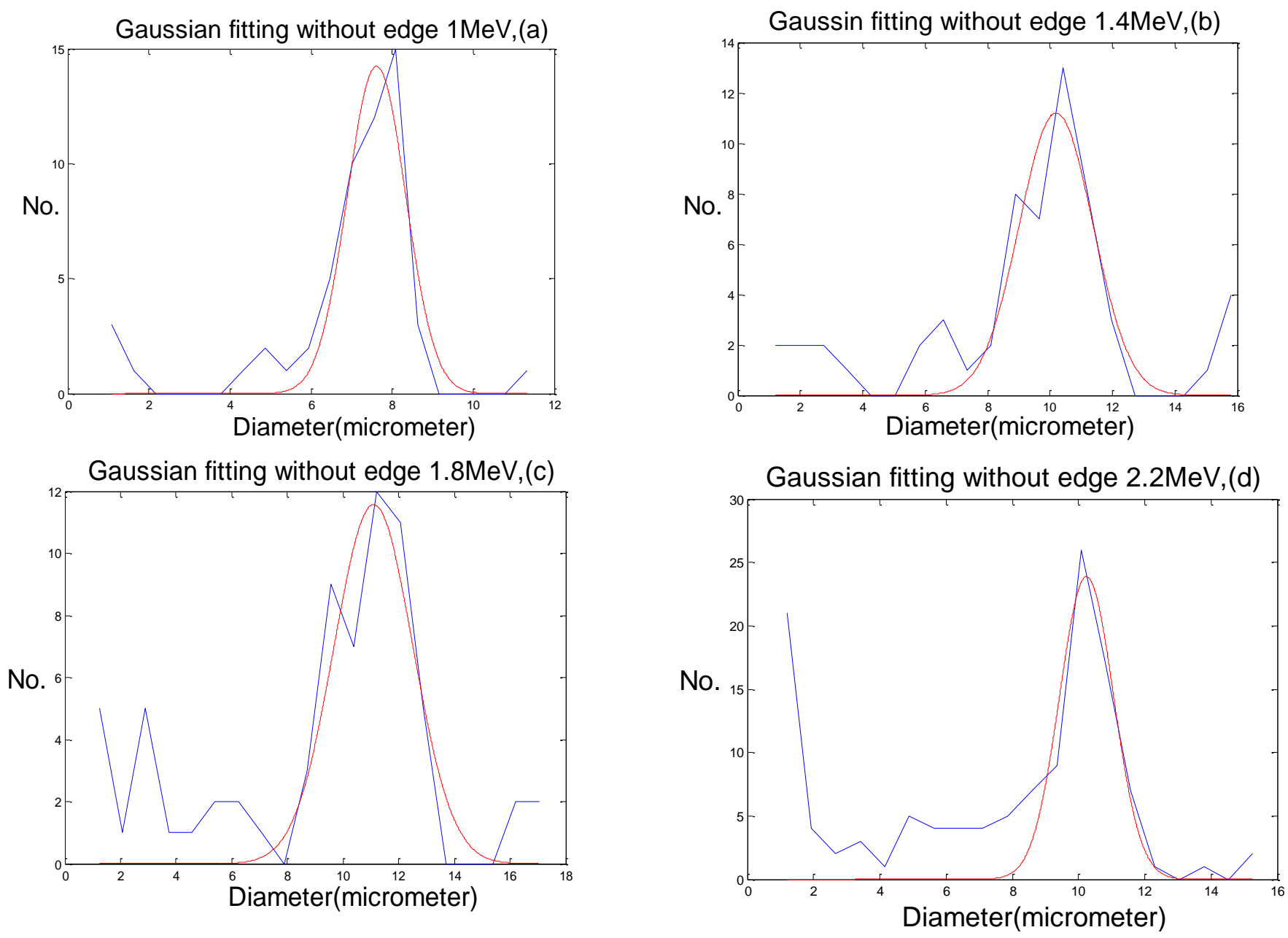


$$
\text { فراس محمد علي الجميلي و قاسم يحيى قاسم }
$$
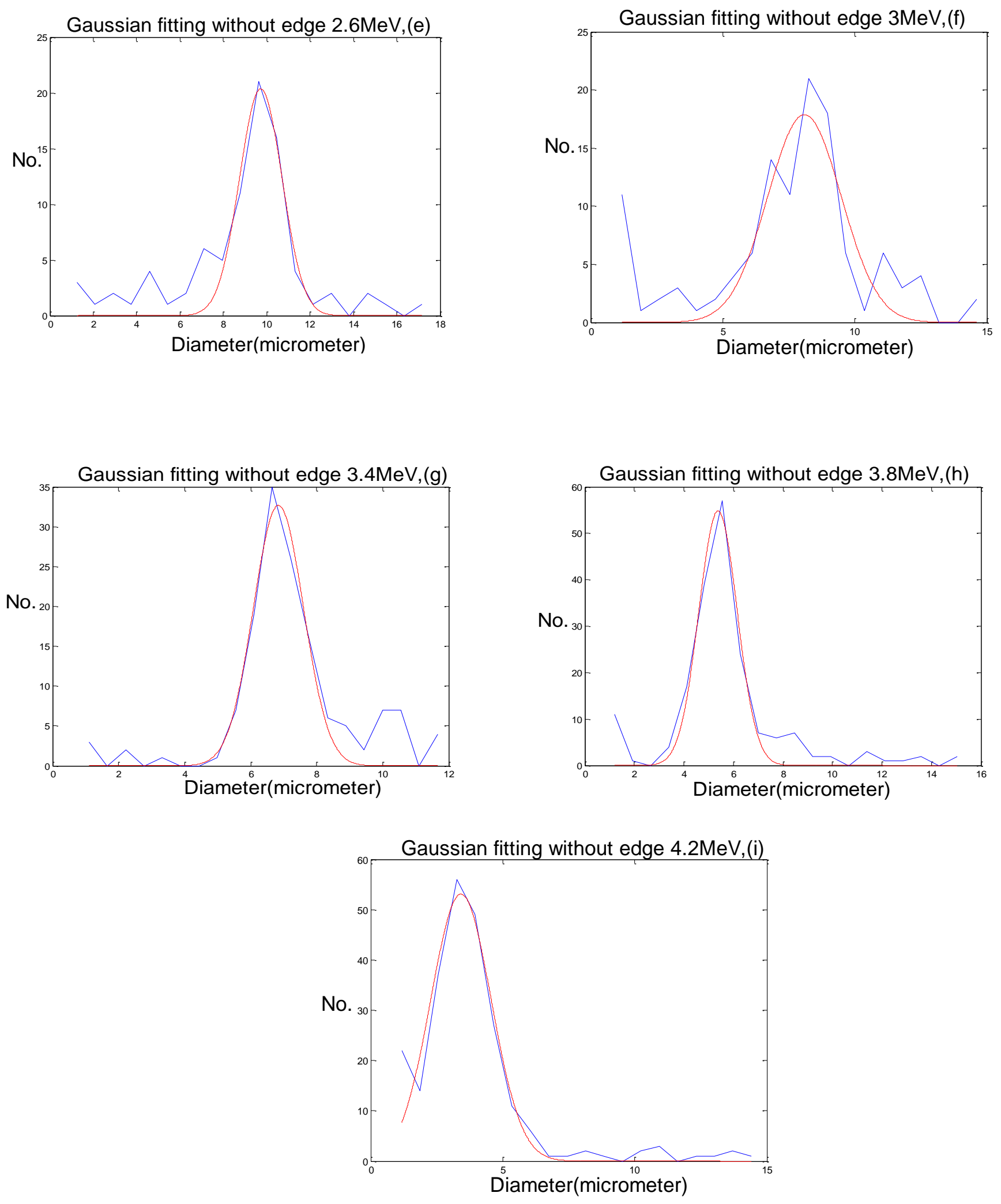
الشكل a,b,c,d,e,f,g,h,i , العلاقة بين مكررات كثافة اعداد الآثار طبقاً لأقطارها للكاشف LR-115 عند زمن قشط (120min) قبل ادخال تقنية كشف الحافة للأثر النووي ويعد اجراء الملاعمة بتوزيع كاوس التي تضمنها برنامج

.(Gauss Track)

المعالجة الصورية لسطح الكاشف باستخدام برنامج " Wbl Track ": اجريت المعالجات الصورية للكاشف LR-115 من خلال برنامج Wbl Track عند أفضل زمن قشطي (120 min) الذي يُظهر أفضل قدرة تحليل طاقي للكاشف وأقل إنحراف معياري الذي بدوره يعطينا معاملات وخواص الكاشف LR-115 وكما مبين في الجدول (2). اجريت الملاءمة بين مكررات اعداد الآثار طبقاً لأقطارها وللطاقات المستخدمة جميعها بعد إجراءها باستخدام توزيع ويبل كما مبين في الثكل (7).

الجدول 2: أعداد الآثار وأقطارها وعرض الطيف والإنحراف المعياري وقرة التحليل الطاقي (R) للكاشف LR-115 وللطاقات جميعها عند زمن القثط الأمثل (120min) بعد إجراء الملاعمة بتوزيع ويبل قبل إدخال تقتية كثف الحافة التي

تضمنها برنامج ( Wbl Track).

\begin{tabular}{|c|c|c|c|c|c|}
\hline Energy $(\mathrm{MeV})$ & $\mathrm{D}(\mu \mathrm{m})$ & $\mathrm{FWHM}(\mu \mathrm{m})$ & S.d & $\mathrm{R}$ & No.of track \\
\hline 1 & 7.578 & 3.6364 & 1.5448 & & 57 \\
\hline 1.4 & 10 & 7.2727 & 3.0895 & 0.3753 & 57 \\
\hline 1.8 & 11.2121 & 6.06 & 2.5746 & 0.6873 & 62 \\
\hline 2.2 & 10.6 & 3.6364 & 1.545 & 0.7920 & 86 \\
\hline 2.6 & 9.697 & 6.6667 & 2.8321 & 0.4717 & 78 \\
\hline 3 & 8.78 & 4.545 & 1.9303 & 0.4873 & 100 \\
\hline 3.4 & 7.87 & 3.93 & 1.673 & 0.3324 & 139 \\
\hline 3.8 & 6.36 & 5.45 & 2.317 & 0.1726 & 174 \\
\hline 4.2 & 4.2424 & 5.4545 & 2.317 & 0.1287 & 222 \\
\hline
\end{tabular}

يبين الثكل (7) العلاقة بين مكررات كثافة اعداد الآثار طبقاً لأفطارها وللطاقات المستخدمة جميعها بعد إجراء عملية الملاعمة باستخدام توزيع وييل. 


$$
\text { فراس محمد علي الجميلي و قاسم يحيى قاسم }
$$
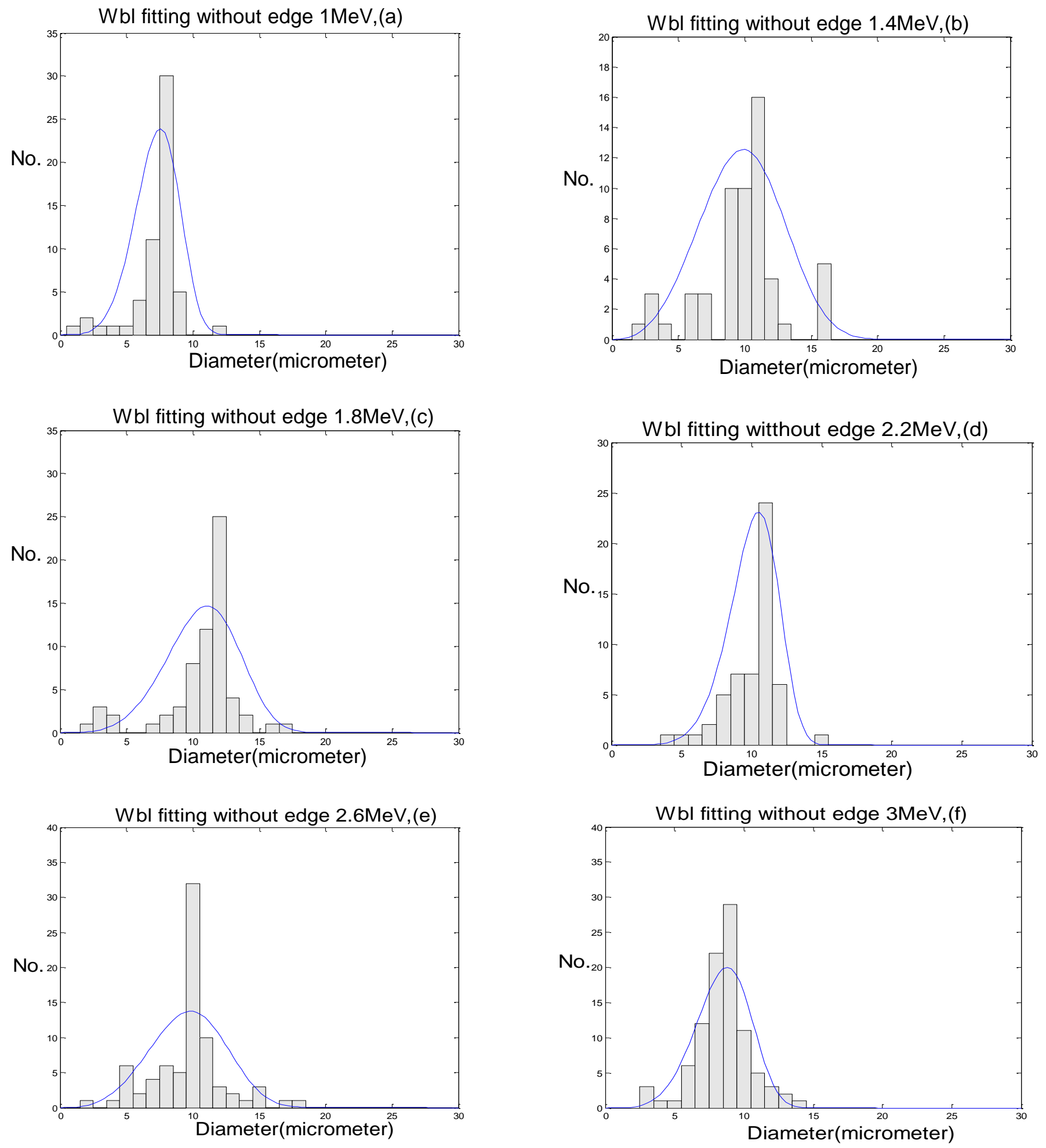

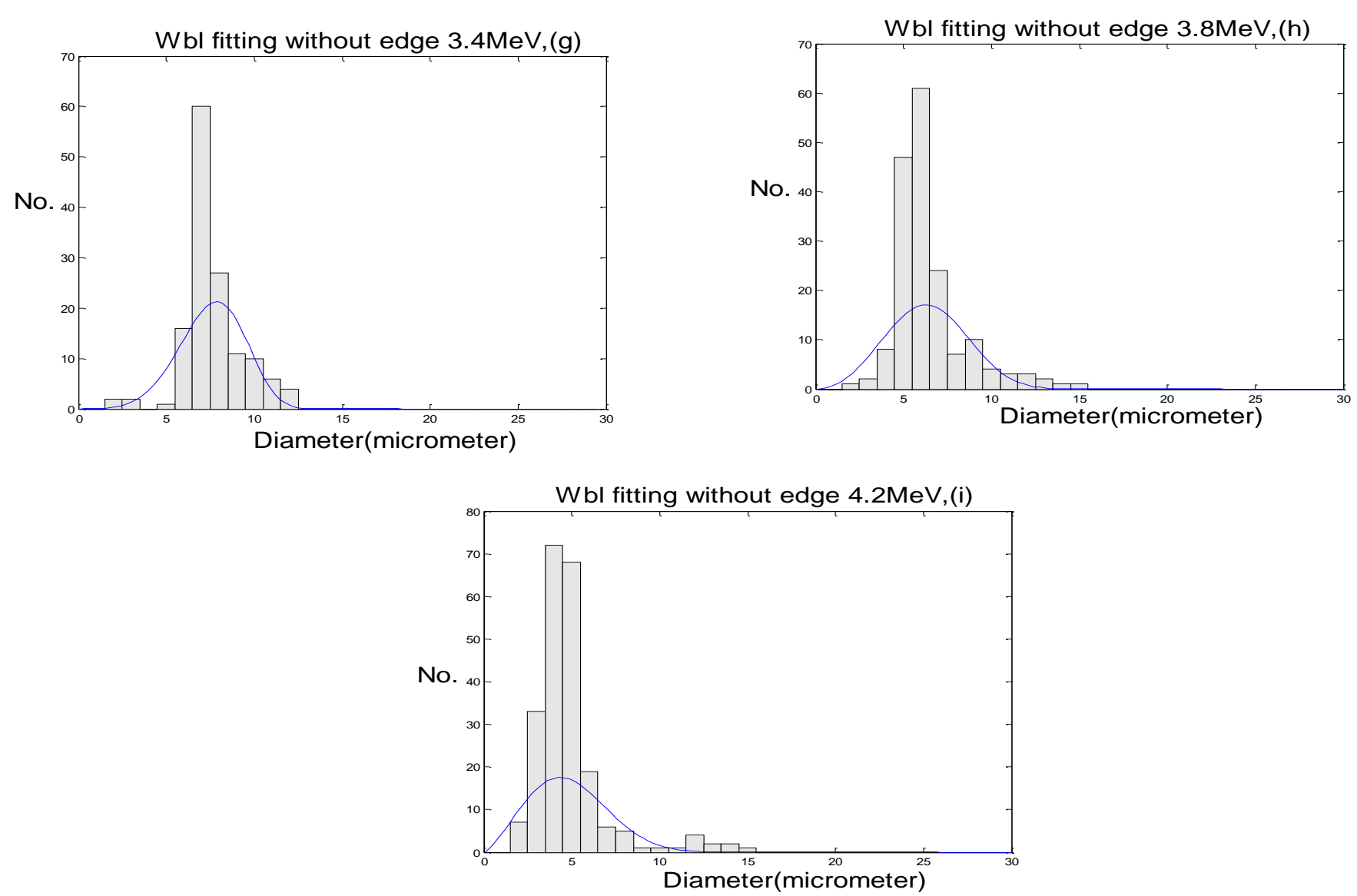

الثكل 7,a,b,c,d,e,f,g,h,i العلاقة بين مكررات كثافة اعداد الآثار طبقاً لأقطارها للكاشف LR-115 عند زمن قثط (120 min) قبل Wbl )

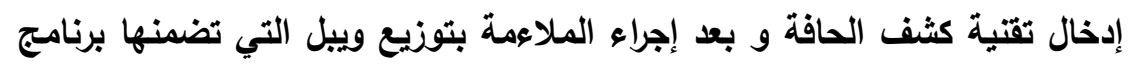
.(Track

\section{: Edge detection technique تقنية كثف الحافة}

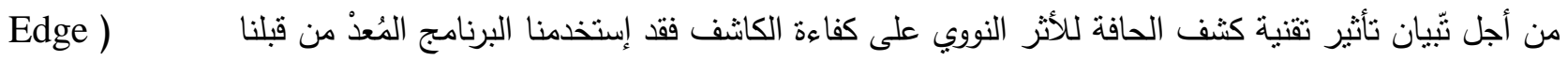

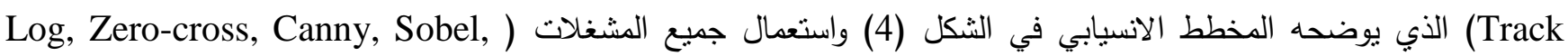
(Prewitt, Roberts

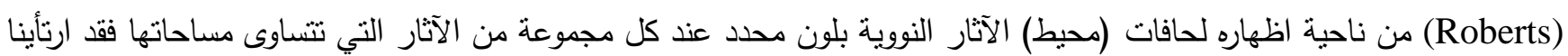

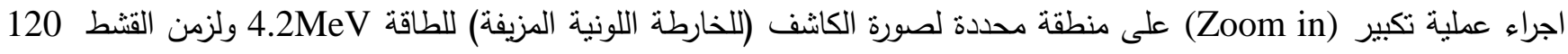
min (على سبيل المثال) وللمشغلات جميعها وكما مبين بالثكل (8). 


$$
\text { فراس محمد علي الجميلي و قاسم بحيى قاسم }
$$

Canny edge

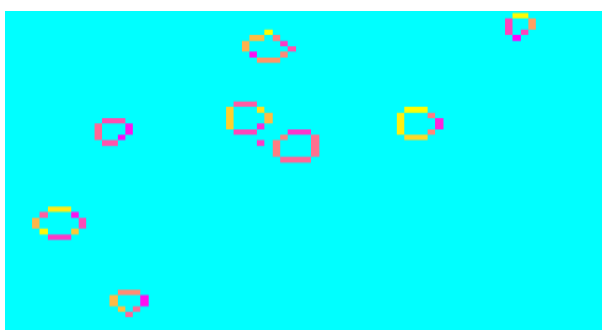

Prewitt edge

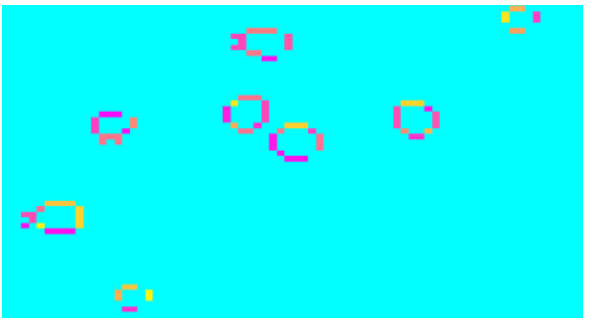

Zero cross edge

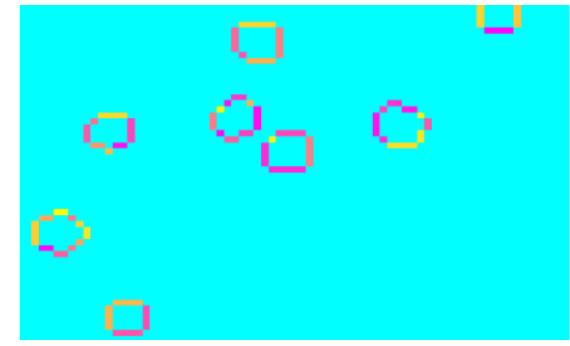

الثكل 8: حافة الأثر النووي عند الطاقة 120min وللمشغلات جميعها لمنطقة محدة سطح الكاشف (Zoom in) بإجراء عملية

ادخلت ثقنية كثف الحافة على البرنامجين (Gauss Track) و (Wbl Track) وتم للحصول على معاملات الأثز النووي وخواص الكاشف وذلك ما يوضحه الجدول (3) و الجدول (4). واجريت عملية الملاءمة على كلا البرنامجين بعد إدخال هذه التقنية كما موضح في الثكلين (9 و 10).

الجدول 3 : أعداد الآثار وأقطارها وعرض الطيف والإنحراف المعياري وقدرة التحليل الطاقي للكاشف LR- 115 وللطاقات جميعها عند زمن القشط الأمثل(120min) بعد إدخال المشغل Roberts في تقنية كثف الحافة وياستخدام

\section{برنامج Gauss Track}




\begin{tabular}{|c|c|c|c|c|c|}
\hline Energy $(\mathbf{M e V})$ & D $(\mu \mathbf{m})$ & FWHM $(\mu m)$ & S.d. & R & No. of track \\
\hline 1 & 5.3323 & 0.6757 & 0.287 & & 57 \\
\hline 1.4 & 6.2544 & 0.6226 & 0.2645 & 0.1173 & 63 \\
\hline 1.8 & 6.7597 & 0.4976 & 0.2114 & 0.1386 & 96 \\
\hline 2.2 & 6.5717 & 0.7387 & 0.3138 & 0.3288 & 104 \\
\hline 2.6 & 6.1082 & 0.6489 & 0.2756 & 0.1245 & 103 \\
\hline 3 & 5.541 & 0.9303 & 0.3952 & 0.0994 & 134 \\
\hline 3.4 & 5.0393 & 0.6812 & 0.2894 & 0.1004 & 144 \\
\hline 3.8 & 4.4492 & 0.7736 & 0.3286 & 0.0685 & 188 \\
\hline 4.2 & 3.7094 & 1.0453 & 0.444 & 0.0615 & 276 \\
\hline
\end{tabular}

الجدول 4 : أعداد الآثار وأقطارها وعرض الطيف والإنحراف المعياري وقدرة التحليل الطاقي للكاشف LR- 115 وللطاقات جميعها عند زمن القشط الأمثل(120min) بعد إدخال المشغل Roberts في تقنية كثف الحافة باستخدام Wbl Track

\begin{tabular}{|c|c|c|c|c|c|}
\hline Energy $(\mathbf{M e V})$ & $\mathbf{D}(\boldsymbol{\mu} \mathbf{m})$ & FWHM $(\boldsymbol{\mu m})$ & S.d. & R & No. of track \\
\hline 1 & 5.1515 & 2.4242 & 1.0298 & & 61 \\
\hline 1.4 & 6.0606 & 3.0303 & 1.2873 & 0.4996 & 58 \\
\hline 1.8 & 6.6667 & 3.0303 & 1.2873 & 0.625 & 69 \\
\hline 2.2 & 6.3636 & 1.2121 & 0.5149 & 0.6998 & 55 \\
\hline 2.6 & 6.0606 & 3.3333 & 1.416 & 0.6251 & 83 \\
\hline 3 & 5.7576 & 2.12 & 0.9011 & 0.6267 & 98 \\
\hline 3.4 & 5.4545 & 1.5152 & 0.6436 & 0.3688 & 141 \\
\hline 3.8 & 4.8485 & 2.1212 & 0.9011 & 0.1667 & 177 \\
\hline 4.2 & 3.9394 & 2.4242 & 1.0298 & 0.1318 & 231 \\
\hline
\end{tabular}

يبين الثكل (9) العلاقة بين مكررات كثافة اعداد الآثار طبقاً لأقطارها وللطاقات المستخدمة جميعها بعد إجراء عملية الملاعمة باستخدام توزيع كاوس بعد إدخال تقنية كثف الحافة
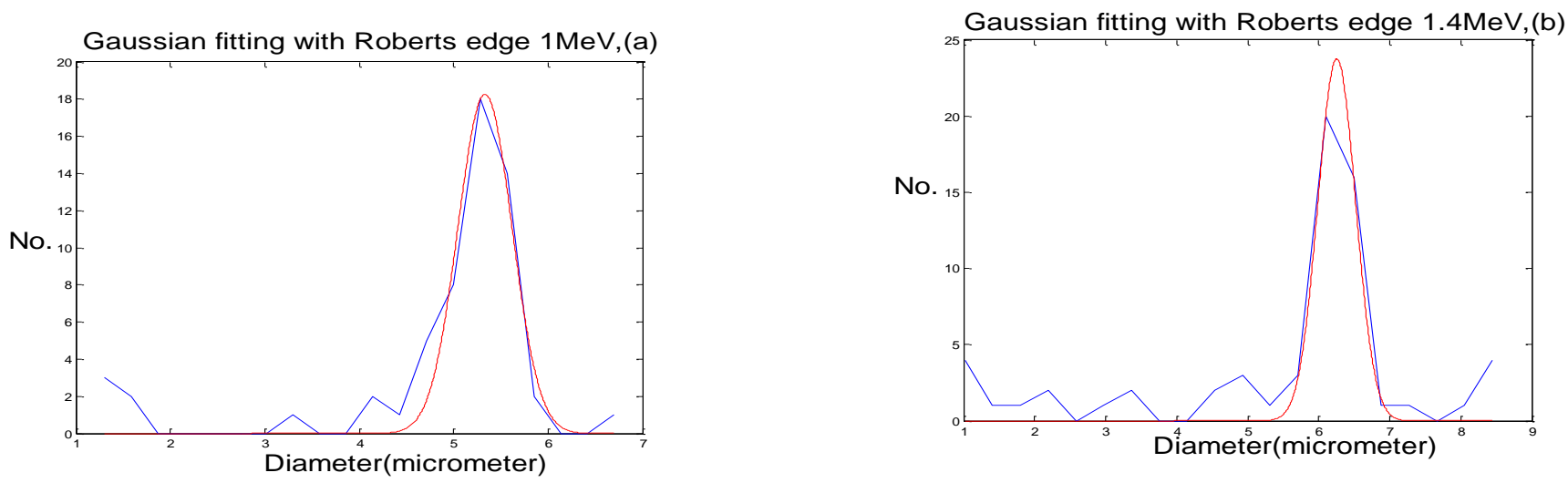
فراس محمد علي الجميلي و قاسم يحيى قاسم
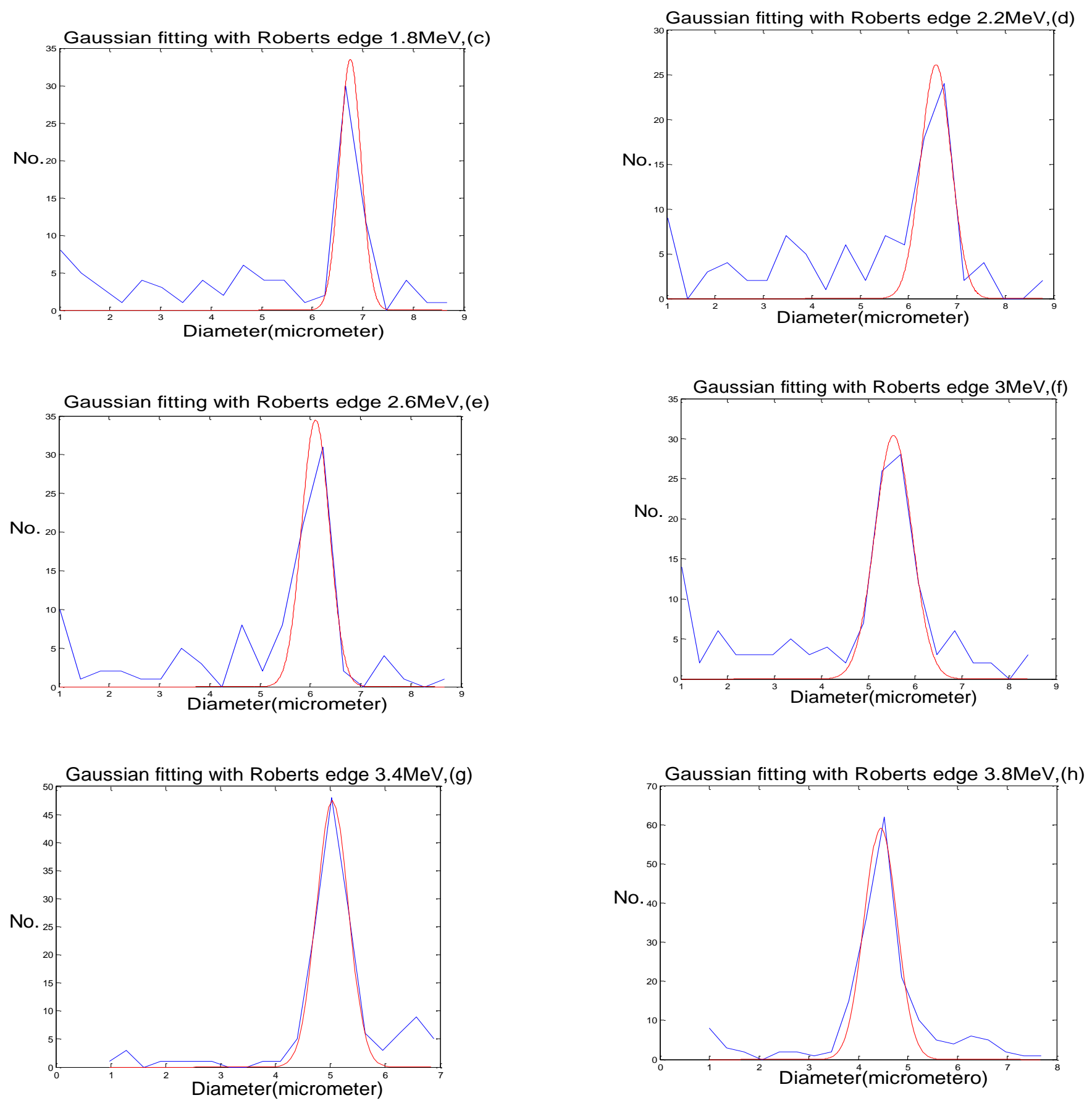


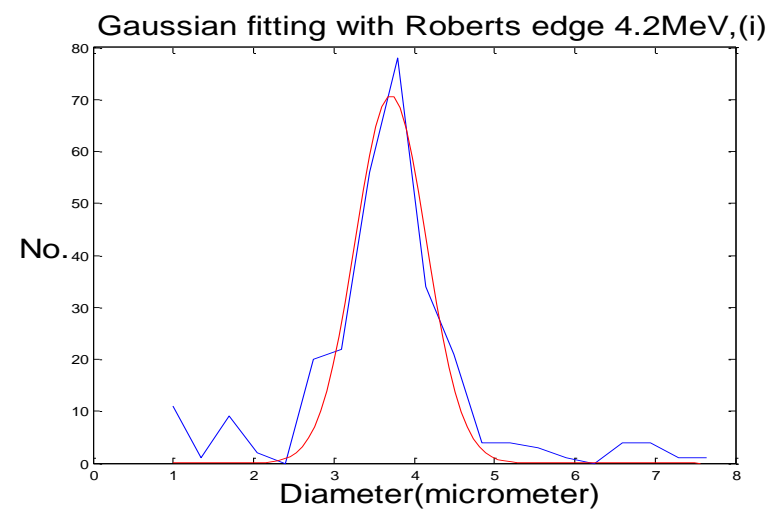

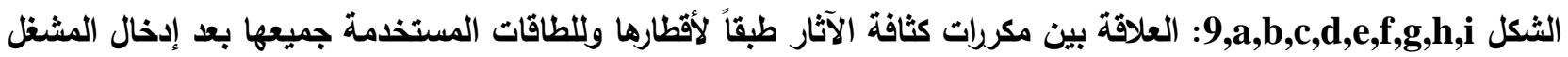

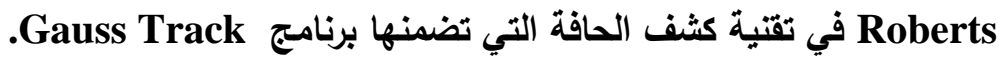

يبين الثكل (10) العلاقة بين مكررات كثافة اعداد الآثار طبقاً لأقطارها وللطاقات المستخدمة جميعها بعد إجراء عملية الملاءمة باستخدام توزيع وييل بعد استخدام ثقنية كثف الحافة
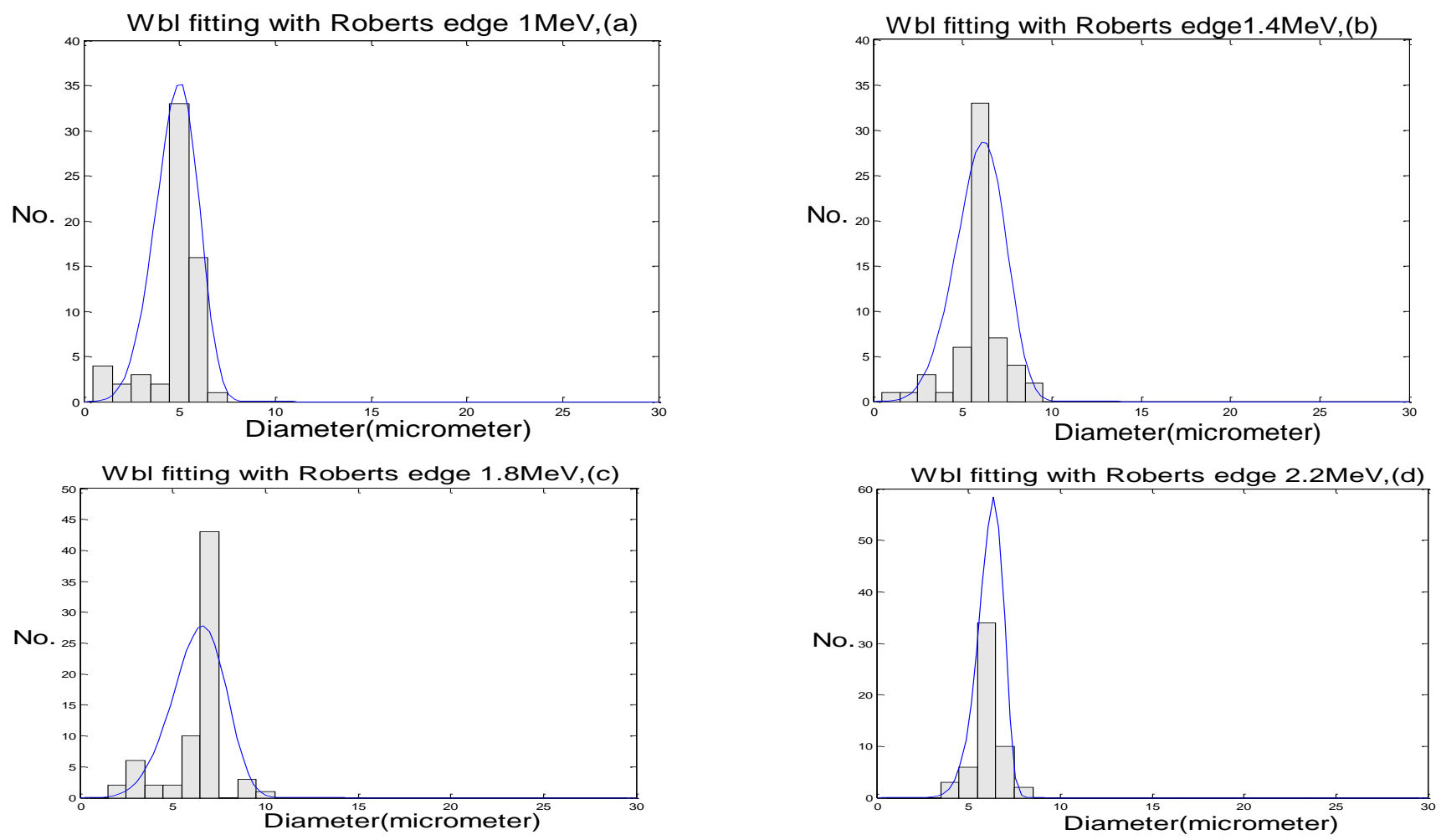


$$
\text { فراس محمد علي الجميلي و قاسم بحيى قاسم }
$$
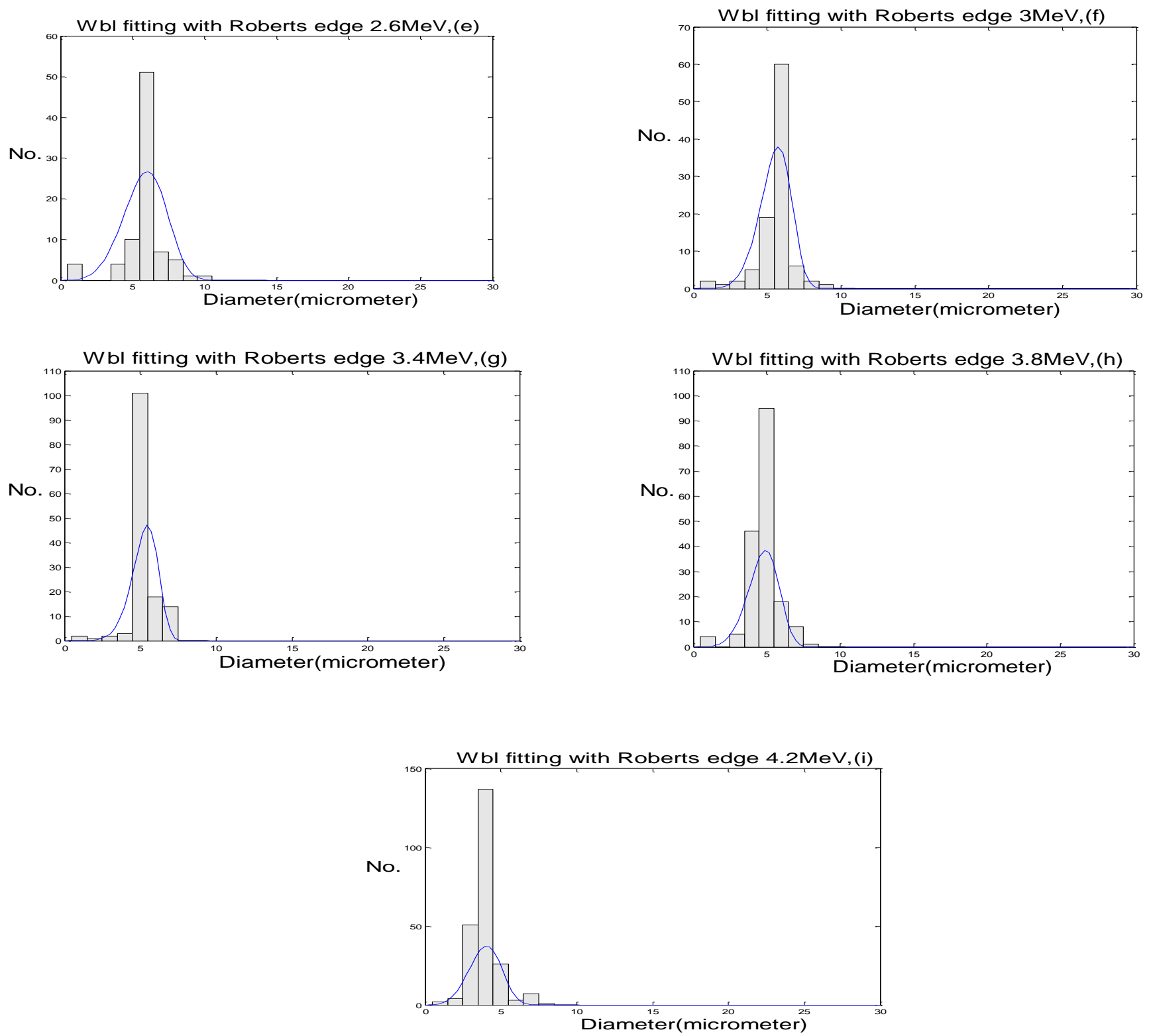

الشكل 10,a,b,c,d,e,f,g,h,i العلاقة بين مكررات كثافة الآثار طبقاً لأقطارها وللطاقات المستخدمة جميعها بعد إدخال المشغل

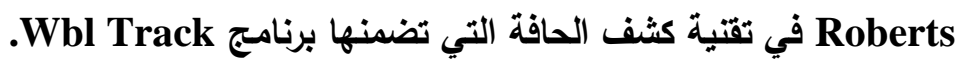

حيث نلحظ من الأشكال(6,7,9,10) المثبتين في أعلاه أن هناك زحزحة لأطياف التوزبع على طول المحور X بإتجاه تتاقص الأقطار كدالة لطاقات الجسيمات الساقطة على الكواثف.

اظهرت نتائج الجداول (1,2,3,4) أن لتقنية كثف الحافة من خلال المشغل Roberts القابلية على تحسين كفاءة الكاشف من خـال استقصاءه اثارٍ اضـافية ذلك بالتغلب على ظاهرة التداخل التي تظهر في الآثار • وعند مقارنة نتائج الجدولان(1,3) لقيم قدرة التحليل الطاقي قبل إذخال تقنية كثف الحافة وبعدها في برنامج Gauss Track أن تللك الخاصية طرأ عليها بعض التحسن النوعي

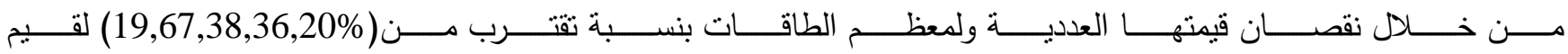
لطاقات(1.4,1.8,2.6,3,3.4MeV)(على التوالي، أماعند الطاقات (2.2,3.8,4.2MeV) فقد أعطت نسب منقاربة لقيم قدرة التحليل 
قبل إدخال تقنية كثف الحافة وبعدها. تُعد هذه النسبة من الزيادة نسبة لايستهان بها لكون قدرة التحليل الطاقية من الخواص الرئيسة والمهمه وهذا يعني بإمكان الكاشف ان يتحرى' عن عناصر مشعة أخرى' بنسبة مقاربه لنسبة الزيادة في قدرته التي طرأت بعد نطبيق

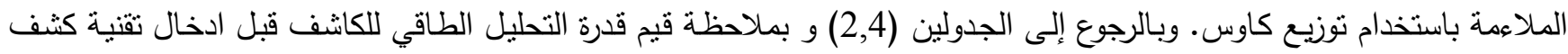
الحافة وبعدها باستخدام برنامج Wbl Track نجد أن تلك الخاصية لم يطرأ عليها تغيير ملحوظ من حيث تحسينها أو تطويرها نوعياً إلا في بعض الطاقات مما يدل على أن إدخال تقنية كثف الحافة خلال ملاعمة توزيع وييل لم تؤدي دوراً في تطوير أوتحسين هذه بأن الخاصيه المهمه من خواص الكواثف، أما من حيث السلوك فقد حافظت تلك الخاصيه على سلوكها فيما يخص اعتماديتها على قطر الآثز وطاقة جسيمات ألفا الساقطة وتحسنت نوعياً (قلت عددياً) بإزدياد طاقة جسيمات. وبالعودة إلى الجداول (1,2,3,4) نجد أن نسبة

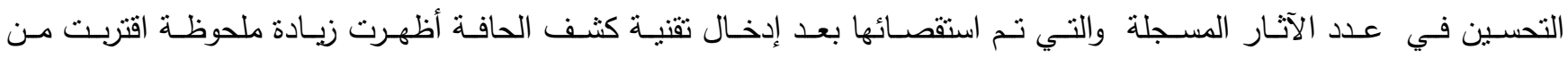

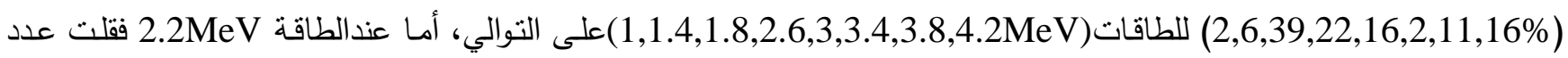

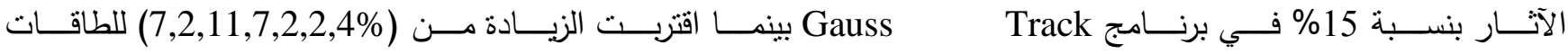
Wbl على التوالي بينما قلت بنسبة (2.4.4.1.8,2.6,3.4,3.8,4.2MeV) Track ذللك سينعكس بالتأكيد على تحسين قدرة الكاثف بالتحري عن اثارٍ لم يسجلها مسبقاً.تنيّن من الثكل(8) أن جميع المشغلات (Log, Zero-cross, Canny, Sobel, Prewitt, Roberts) وصحيحه للآثار النووية ماعدا المشغل (Roberts) إذ يتضح أن لهذا المشغل القابلية في تمييز آثاراً جديدة كانت متداخلة ومتراكبة بعضها مع البعض الأخر وبهذا يكون لـه القابلية بالتغلب على ظاهرة التداخل overlapping phenomen التي تحدث عند ثقارب

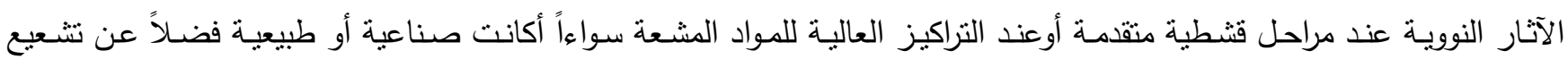
الكاثف بطاقات عاليه. اخفقت بقية المشغلات في التغلب على تلك الظـاهرة ويعود السبب في ذلك إلى أن الحافات الناتجة عند استخدامها أنتجت بِألوان متفاوتة ومختلفة ومتقطعة في محيطها الواحد عند أخذ الخارطة اللونية المزيفة عكس المشـل Roberts الذي قام بفصل الآثار وإحصائها طبقاً لمساحاتها وأعطى لون محدد لكل مجموعة وبمحيط ذو لون محدد كما يتضح من خلان الجدوال المذكورة في أعلاه بأن سلوك قدرة التحليل الطاقي يعتمد بشكل أساسي على معدلات أقطار وطاقة جسيمات ألفا الساقطة حيث إزدادت

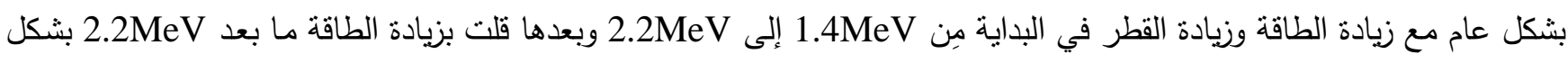

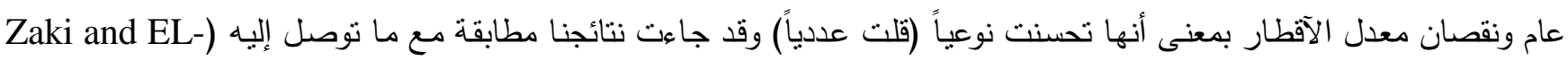
(Shaer, 2007 و) و (الجبوري، 2004) ومن الجدير بالذكر أن البحوث في اعلاه تتاولت قدرة التحليل الطاقي للكواثف إبتداءً من الطاقة 2MeV وأعلى منها ولذا ظهر لهم سلوك تلك الخاصية بأنه خطي ويتجه عكسياً مع زيادة الطاقة، وبهذا ابتعدوا عن دراسة تلك الخاصيه عند الطاقة الأقل من 2MeV والتي يظهر عندها أعظم إمتصاص للطاقة وأكبر قطر للآثر أي مناطق الذروة لأقطار الآثار طبقاً لطاقاتها ولإعتماد قدرة التحليل الطاقي أعتماداً أساسياً على تلك القيم قمنا بدراستها في ذلك الطيف

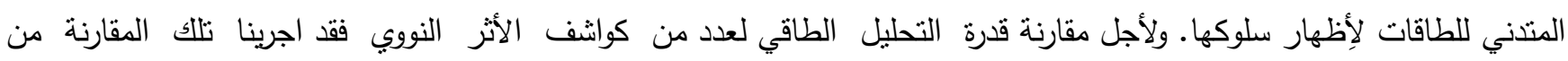

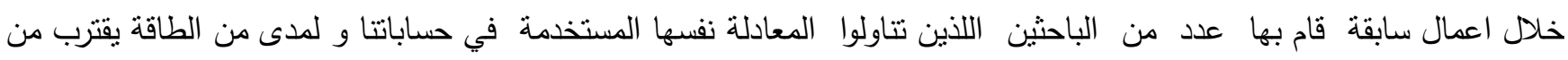

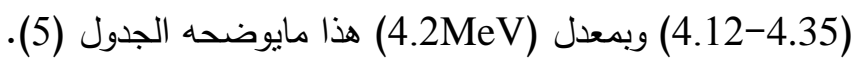


فراس محمد علي الجميلي و قاسم يحيى قاسم

\begin{tabular}{|c|c|c|c|}
\hline المصدر & نوع الكاثف & قرة التحليل الطاقي بالالة القطر & نوع الملاعمة \\
\hline Amero et al., 2001 & CR-39 & O.18 & توزيع كاوس \\
\hline Zaki and EL-Shaer, 2007 & CR-39 & 0.2802 & توزيع لورنتز \\
\hline الجبوري،2004 & PM-355 & 0.23 & توزيع كاوس \\
\hline Present Work & LR-115 & 0.054 & توزيع كاوس \\
\hline Present Work & LR-115 & 0.047 & توزيع ويبل \\
\hline
\end{tabular}

$\left(\frac{\Delta E}{E}\right)_{A}$ حساب قدرة التحليل الطاقي بدلالة المساحلة

إعتماداً على التحويرات التي أجريناها على البرنامج Gauss Track بعد إجراء عملية الملاعمة على أطياف التوزيع بين مكررات عدد الآثار طبقاً لمساحاتها وحصولنا على بعض المعطيات التي تُكننا من حساب قدرة التحليل الطاقي بدلالة مساحة الآثر • وبناءً

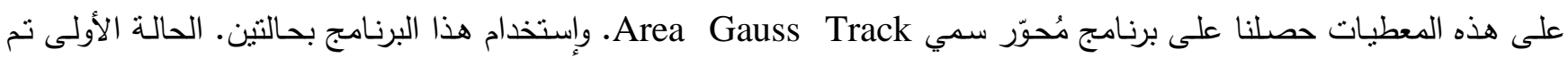
إستخدامه بدون تقنية كثف الحافة، أما الحالة الثانية فقد نم استخدام البرنامج بعد إدخال تقنية كثف الحافة وكما موضح بالجدول (6). وقد تحسنت نوعيا(قلت عدديا) عند الطاقات العالية على عكس الطاقات الواطئة ضمن المدى المستخدم بالموازنة مع الملاعمة طبقا للقطر

الجدول 6: عدد الآثار ومساحاتهم والقدرة التحليلية للكاشف بدلالة المساحة وعرض الذروة قبل إدخال تقتية كثف الحافة ويعدها.

\begin{tabular}{|c|c|c|c|c|c|c|}
\hline Energy(MeV) & \multicolumn{2}{|c|}{ Without edge for Area Gauss Track } & \multicolumn{3}{c|}{$\begin{array}{c}\text { With edge Roberts for Area } \\
\text { Gauss Track }\end{array}$} \\
\hline & Aav. (Pixel) & FWHM & R & Aav.(pixel) & FWHM & R \\
\hline 1 & 86.6914 & 29.0074 & & 41.1069 & 8.8654 & \\
\hline 1.4 & 152.5 & 93.6395 & 0.1553 & 58.2404 & 11.4262 & 0.0987 \\
\hline 1.8 & 177.5 & 121.6504 & 0.5382 & 64.2410 & 17.8749 & 0.3052 \\
\hline 2.2 & 153.9 & 72.3460 & 0.4110 & 57.0930 & 13.8736 & 0.2221 \\
\hline 2.6 & 136.6 & 70.6693 & 0.3444 & 54.4862 & 9.8585 & 0.3793 \\
\hline 3 & 98.5 & 77.169 & 0.1408 & 47.6547 & 14.0305 & 0.1249 \\
\hline 3.4 & 66.4676 & 27.4095 & 0.1020 & 36.8796 & 8.9690 & 0.0667 \\
\hline 3.8 & 42.0987 & 29.27 & 0.0646 & 27.9605 & 10.9560 & 0.0621 \\
\hline 4.2 & 12.7686 & 33.97 & 0.0539 & 16.8919 & 9.8460 & 0.0470 \\
\hline
\end{tabular}

بينت نتائج الجدول (6) لقيم قدرة التحليل الطاقي قبل إدخال تقنية كثف الحافة وبعدها ببرنامج Area Gauss Track طرأ عليها بعض التحسن النوعي من خلال نقصان قيمتها العددية ولمعظم الطاقات بنسبة قربت من(36,43,46,11,35,4,13\%)

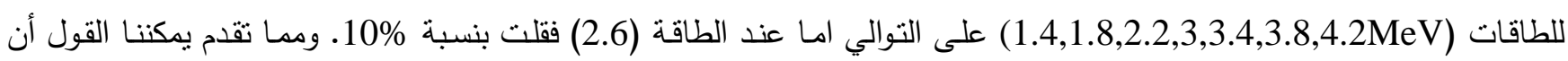
قدرة التحليل الطاقي بدلالة المساحة تكون أفضل للطاقات العالية ما بعد الطاقة 2.6MeV (ضمن المدى المستخدم) بالموازنة مع قدرة التحليل الطاقي بدلالة القطر عند الطاقات نفسها قبل ادخال تقنية كثف الحافه وبعدها هذا ماوضحته الجداول(1,2,6). الأستنتاجات 
1- تخضع جميع التوزيعات لأقطار الآثار مع مكررات كثافاتها العددية ولاسيما عند زمن القشط الأمنل لتوزيع كاوس وتوزيع وييل في

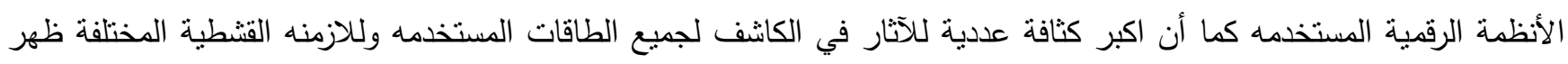
عند متوسط القطر للآنار لكل من التوزيعات (توزيع كاوس و ويبل). 2- إن الجسيمات المشعع بها الكاثف وإن كانت تمنلك طاقة محددة إلا أنه يحصل تباين في فقدانها للطاقة خلال مرورها بمادة الكاشف وهذا مايظهر من التوزيعات الكاوسية وتوزيعات وييل للطيف الطاقي لكل طاقة مستخدمة ويظهر أقل تباين في الطاقة الأطياف التي تمتلك أقل انحراف معياري. 3- توفر برامج المعالجة الصورية الرقمية والمستخدمه في هذه الدراسة بيانات ومعطيات فيما يتعلق لبعض مُعامِلات الأثر التي تؤدي إلى تحديد بعض خواص الكاشف كقدة التحليل الطاقي وكفاءة الكاشف على أستقصاء وعد آثار (من خلال اقتفاء عدد الآثار) فضلاً عن إستتباط بعض النتائج الأحصائية. 4- تستغرق الأنظمة الرقمية المستخدمه وقتاً لايتجاوز 6sec في المعالجات الصورية والذي يعتبر زمنا قصيراً بالمقارنة مع الوقت المستهلك بِاسلوب القياس الروتيني (اليدوي) فضلاً عن الدقة العالية التي يبديها النظام.

5- اظهرت تقنية كثف حافة الأثر النووي باستخدام (Roberts) افضليه في تحسين قدرة التحليل الطاقي للكاشف في اطياف التوزيع الكاوسي ولاسيما عند الطاقات الواطئه ضمن المدى المستخدم، في حين لم تظهر تلك التحسينات في أطياف توزيع وييل. 6- تبين بان قدرة التحليل الطاقي يمكن الحصول عليها من خلال الملاءمة التي نم اعتمادها طبقاً لمساحات الآثار. المصادر العربية

الجبوري، محمد محمود صالح(2004). قدرة التحليل الطاقي لكاثف الأثر النووي البلاستيكي PM-355 لجسيمات ألفا وتأثير المعالجة الحرارية. جامعة الموصل، كلية التربية، رسالة ماجستير كموصل، العراق.

الجميلي، فراس محمد (2009)، قياس الجرعات الإشعاعية الكهرومغناطيسية باستخدام كواثف الأثر النووي و تحديد كفاءاتها الذاتية مع إدخال المعالجة الصورية الحاسوبية في القياس. جامعة الموصل، كلية العلوم، اطروحة دكتوراه، الموصل، العراق. عبد الله، علي عطية; الدركزلي، شذى سليمان ; الياس، مازن مانؤييل (1990)، " الفيزياء النووية التطبيقية ". مطابع التعليم العالي، بغداد، العراق.

العريبي،علياء قصي احمد تقي (2008). تطبيق تقنيات تقليدية وذكائية لتحسين التباين في الصور الرقمية، مجلة الرافدين لعلوم الحاسبات والرياضيات، 5(2) ، (2)، 135-158.

\section{المصادر الأجنبية}

Amero, C.; Golzarri, J.I.; Izerrouken, M.; Espinosa, G. (2001). ${ }^{148} \mathrm{Gd},{ }^{238} \mathrm{U},{ }^{239} \mathrm{Pu}$ and ${ }^{244} \mathrm{Cm}$ Alpha Particle Energy Analysis Using Tracks in Solids.Radi. Meas., 34 , 341-343.

Cember, H. (1996). "Introduction of Health Physics", $3^{\text {rd }}$ ed., McGraw Hill, Pergamon Press- London, $129-131$.

Moses, E . ;Bassuah, B. ;Pual, K.; Osborne, C. (2007). Track Analysis of Laser -illuminated Etch Track Detectors Using an Opto-digital Imaging System,Meas. Sci. and Tech., 18, Isse 11, 3651-3660.

Mostofizadeh, A.; Sun, X.; Kardan, M.R.(2008). Improvement of Nuclear Track Density Measurements Using Image Processing Techniques, Ame. J. of App.Sci. 5 (2). 71-76. 


$$
\text { فراس محمد علي الجميلي و قاسم يحيى قاسم }
$$

Muraleedharan, G.; Rao, A.G.; Kurup P.G.; Nair, N. Unnikrishnan; Sinha Mourani (2007). "Coastal Engineering". 54 (8), 630-638.

Palacias, D.; Sajo-Bohus, L.; Barros, H.; Fusella E.; Avila, Y. (2011). Analysis and Correction of Track Overlapping on Nuclear Track D, etector, Revista Mexicana De Fisica, 57(1), (34-39)

Patiris, D.L.; Blekas, K.; loannides, K.G.(2007). TRIACII. A Matlab Code for Track Measurements From SSNT Detectors, Comp. Ph. Comm. 177, Issue 3, 329-338.

Patiris, D.L.; Blekas, K.; Loannides, K.G. (2006). TRIAC: Acode for Track Measurements Using Image Analysis Tools, Nucl. Inst. And Method in Physics Research, 244 , 392-396.

Sujatha, C.; Selvathi, D.(2012). An Optimal Solution for Image Edge Deteaction Problem Using Simplified Gabor Wavelet, Inter.J.l of Comp. Sci., Engineering and Information Technology (IJCSEIT), l.2,( No.3), 99-115.

Zaki, M.F.; EL-Shaer, Y.H. (2007). Particularization of Alpha Contamination Using CR-39 Track Detectors, Indian Academy of Sciences, 69, (No. 4),(567-574). 